\title{
Closed mitral commissurotomy-a cheap, reproducible and successful way to treat mitral stenosis
}

\author{
Manuel J. Antunes \\ Clinic of Cardiothoracic Surgery, Faculty of Medicine, University of Coimbra, Coimbra, Portugal \\ Correspondence to: Prof. Manuel J. Antunes. Faculty of Medicine, University of Coimbra, 3000-075 Coimbra, Portugal. Email: mjantunes48@sapo.pt. \\ Provenance and Peer Review: This article was commissioned by the Editorial Office, fournal of Thoracic Disease. The article did not undergo external \\ peer review. \\ Comment on: Xu A, Jin J, Li X, et al. Mitral valve restenosis after closed mitral commissurotomy: case discussion. J Thorac Dis 2019;11:3659-71.
}

Submitted Oct 23, 2019. Accepted for publication Nov 29, 2019.

doi: $10.21037 /$ jtd.2019.12.118

View this article at: http://dx.doi.org/10.21037/jtd.2019.12.118

In the August issue of the Journal, Xu et al. (1), from China, discuss the case of a patient who had a successful reoperation for restenosis of the mitral valve performed 30 years after closed mitral commissurotomy (CMC). The specific aspects of this case were most appropriately commented by several experienced surgeons from different parts of the world. I was now invited by the Editor of this Journal to write a Comment on this paper and its subject.

\section{History of the treatment of the stenotic mitral valve}

CMC was one of the first operations routinely performed on the heart, long before the beginning of the open-heart surgery era brought to us by Gibbon's heart-lung machine in 1953. The first CMC was successfully performed by Elliot Cutler, in 1923, at the Peter Bent Brigham Hospital, Boston, through a median sternotomy, by a transventricular approach and with a tenotomy knife, on a 12 -year-old girl with rheumatic mitral stenosis, who survived the operation (2). This was followed by seven other operations but all patients died; Cutler's colleagues refused to send him more patients and he gave up the operation in 1929. Meanwhile, in 1925, Souttar (3), in London, intervened on the mitral valve via the left atrial appendage, using the index finger to achieve a true mitral commissurotomy, by contrast with Cutler's procedure which opened the valve through the leaflets, causing regurgitation. But, again, Souttar did no other case because the cardiologists never sent him another patient!

The procedure was revisited only more than two decades later, in the late 1940's, by Dwight Harken and Charles
Bayley $(4,5)$ and then became widely accepted. Subsequently, the technique of CMC suffered several modifications, both in the way the mitral valve was accessed and split. Several instruments were created to facilitate the opening of the commissures, culminating with the development of the Tubbs dilator, which became the standard instrument for the procedure (Figure 1).

The CMC was the commonest heart operation performed in the beginning of the second half of the $20^{\text {th }}$ century, especially in the countries of the southern hemisphere where rheumatic disease was (still is) prevalent, but also in Europe and North America. It was performed in hundreds of thousands of patients with excellent immediate and late results that lasted for decades, as it happened in the current case described by $\mathrm{Xu}$ et al. (1). The largest series of $\mathrm{CMC}$ was published in 1991 by Stanley John, from India, and included 5,326 patients with rheumatic mitral stenosis who had a 24-year survival, without requiring a second procedure, of $78.3 \%$ (6). I, then in South Africa, personally performed CMC in more than five hundred patients in the 1970's and 80's. The typical indications for CMC were a tight valve stenosis (orifice area $<1.0 \mathrm{~cm}^{2}$ ) with no or insignificant regurgitation, pliable leaflets and no calcification (Figure 2). Presence of left atrial clot was a clear contraindication.

With the development of open-heart surgery and the introduction of mitral valve repair, open mitral commissurotomy (OMC) started to attract the surgeons' preference, because of the clear advantage of direct observation of the valve anatomy and the possibility of extending the procedure to the subvalvular apparatus also involved in the rheumatic scarring process. Additionally, OMC also permitted the treatment of 


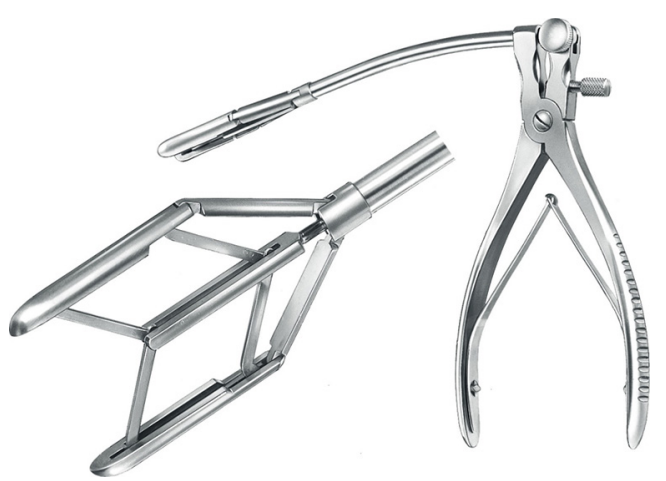

Figure 1 Tubbs dilator used in closed mitral commissurotomy $\left(\operatorname{KLSMartin}^{\odot}\right)$.
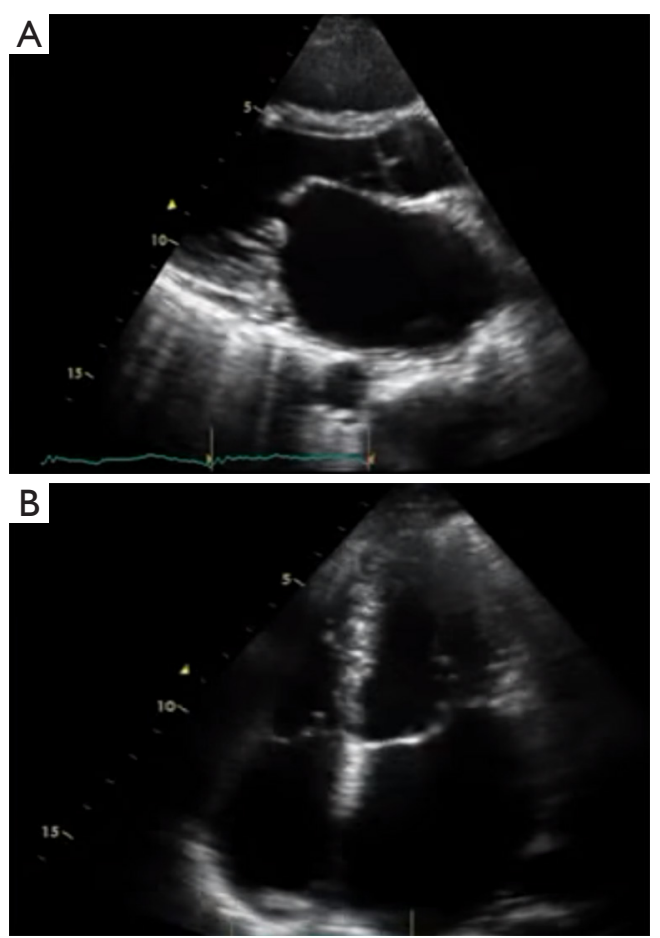

Figure 2 Ecocardiogram of a pliable mitral valve stenosis. (A) Longitudinal view; (B) 4-chamber view. Note the thin and mobile leaflets.

valves with some degree of calcification, which was one of the contraindications to the closed procedure.

Gradually, CMC was abandoned almost everywhere and the final blow was the development of the percutaneous balloon mitral commissurotomy (PMC) by Inoue and colleagues in 1984 (7). This procedure was rapidly adopted by the cardiological fraternity and led to the final demise

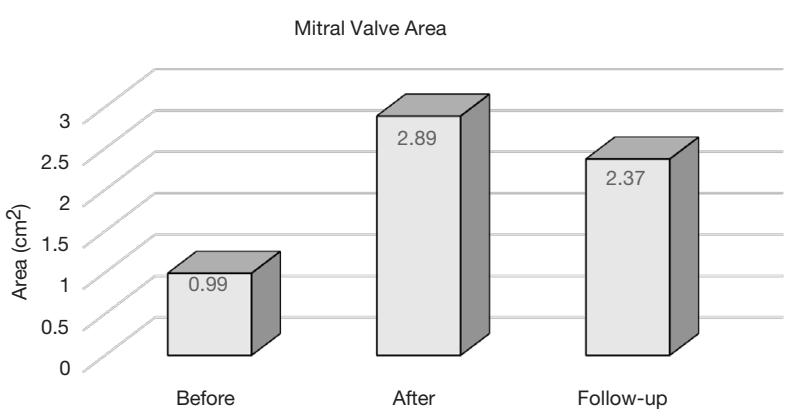

Figure 3 Evolution of mitral valve areas $\left(\mathrm{cm}^{2}\right)$ after open mitral commissurotomy, from before and immediately after surgery to 10 -year follow-up. Post procedural and late follow-up areas are superior to those generally described after the percutaneous procedure [Redrew with data from Antunes et al. (8)].

of CMC and almost disappearance of the OMC, to which (not to the $\mathrm{CMC}$ ) it was initially favourably compared. $\mathrm{My}$ own experience, however, showed that OMC resulted in better post-procedural valve areas and long-term survival (Figure 3) (8). In my view, there is no reason why the results of PMC should be superior to those of CMC; if something, the latter is even a more controlled procedure because of the guidance of the surgeon's finger. But the fact is that the majority of surgeons also gave up the open procedure and most often opt for a direct valve replacement. Hence, even I, who remain relatively critic of the blind PMC, have to admit that it does save many valves that the surgeons would otherwise waste. Nevertheless, I, as well as others, still do not consider surgical commissurotomy an outdated technique (9).

\section{Re-operating after CMC}

Rheumatic valve disease is a continuing inflammatory and scarring process which progressively deforms the mitral valve, inevitably causing re-stenosis and/or regurgitation and leading to the need of re-operations sometime, often decades later. The indications for re-intervention are similar to those applicable to intervention on previously untouched mitral valves. In selected cases, PMC may be appropriate as, indeed, could CMC be.

The majority of cases, however, will require open-heart surgery. Most experienced cardiac surgeons are used to re-operations and this particular one is simpler than the majority: Firstly, because the initial procedure was less invasive; the mediastinum and the pericardium are intact anteriorly and pericardial adhesions are less intense and 
easier to dissect because of the long time passed. Secondly, because the mitral apparatus is mostly untouched and the surgeon can freely use all the techniques applicable to either a conservative or a replacement procedure. In my longer than 40-year experience in cardiac surgery, I had the opportunity of performing many post-CMC reoperations and succeeded in preserving many of these valves, by reopening the commissures, working on the subvalvular structures and, often, adding an annuloplasty. Otherwise, valve replacement in these patients follows the general rules. In these cases, elective reoperation should have a very low operative mortality, not exceeding $1-2 \%$ in patients without significant co-morbidities, which is usually the case.

\section{Re-visiting CMC}

One of the problems of PMC is its high cost and technical exigencies that make it unavailable in still many parts of the underdeveloped world and beyond. By contrast, CMC is a much less expensive procedure and has the advantage that it can be performed even by non-cardiac surgeons. If re-adopted, and I am actively calling for this, it could save thousands of lives in the poor countries of the southern hemisphere, especially in Africa and some parts of Asia. Indeed, there are some places in India where it is still actively practiced $(10,11)$, and a recent study performed in that country showed no statistically significant difference between the immediate results of CMC and of PMC, but better long-term outcomes were obtained by CMC. Furthermore, the procedural cost of CMC was significantly lower than that of PMC (12).

Unfortunately, the vast majority of cardiac surgeons have completely forgotten how to do this technically very simple procedure, and the new generations of surgeons are not even taught how to perform it. Indeed, it has disappeared from most cardiac surgical textbooks (13). Although this operation is not completely exempted from complications, these are usually related to insufficient or inappropriate opening of the valve, most often with leaflet tear, resulting in different degrees of regurgitation that, however, does not necessitate emergency or even urgent correction. Any competent general surgeon who is able to do a left thoracotomy could, therefore, be rapidly trained to perform CMC with almost inexistent mortality (14).

\section{Conclusions}

In summary, CMC was, still is, one of the most reproducible and successful cardiac operations ever performed. It has saved the lives of many hundreds of thousands patients for whom there was no other alternative. It still has the conditions to be a good alternative in many parts of the world where open-heart surgery and even PMC are not readily available or are not at the reach of the economically fragile patient. Naturally, valve replacement may be necessary at a (much) later stage after CMC, especially if performed at a young age, but the reoperation is uniformly feasible and carries a low morbidity and mortality (15).

\section{Acknowledgments}

Funding: None.

\section{Footnotes}

Conflicts of Interest: The author has no conflicts of interest to declare.

Ethical Statement: The author is accountable for all aspects of the work in ensuring that questions related to the accuracy or integrity of any part of the work are appropriately investigated and resolved.

Open Access Statement: This is an Open Access article distributed in accordance with the Creative Commons Attribution-NonCommercial-NoDerivs 4.0 International License (CC BY-NC-ND 4.0), which permits the noncommercial replication and distribution of the article with the strict proviso that no changes or edits are made and the original work is properly cited (including links to both the formal publication through the relevant DOI and the license). See: https://creativecommons.org/licenses/by-nc-nd/4.0/.

\section{References}

1. Xu A, Jin J, Li X, et al. Mitral valve restenosis after closed mitral commissurotomy: case discussion. J Thorac Dis 2019;11:3659-71.

2. Cutler EC, Levine SA. Cardiotomy and valvulotomy for mitral stenosis: experimental observations and clinical notes concerning an operated case with recovery. Boston Med Surg J 1923;188:1023-7.

3. Souttar HS. The surgical treatment of mitral stenosis. Br Med J 1925;2:603-6.

4. Harken DE, Ellis LB, Ware PF, et al. The surgical treatment of mitral stenosis. I. Valvuloplasty. N Engl J Med 1948;239:801-9. 
5. Bailey CP. The surgical treatment of mitral stenosis (mitral commissurotomy). Dis Chest 1949;15:377-97.

6. John S, Shyam Prasad KM, Ravikumar E, et al. Closed commissurotomy for mitral stenosis: Obsolete or relevant? Indian J Thorac Cardiovasc Surg 1991;7:8-12.

7. Inoue K, Owaki T, Nakamura T, et al. Clinical application of transvenous mitral commissurotomy by a new balloon catheter. J Thorac Cardiovasc Surg 1984;87:394-402.

8. Antunes MJ, Vieira H, Ferrão de Oliveira J. Open mitral commissurotomy: the 'golden standard'. J Heart Valve Dis 2000;9:472-7.

9. Detter C, Fischlein T, Feldmeier C, et al. Mitral commissurotomy, a technique outdated? long-term follow-up over a period of 35 years. Ann Thorac Surg 1999;68:2112-18.

10. Akinci E, Değertekin M, Güler M, et al. Less invasive approaches for closed mitral commissurotomy. Eur J Cardiothorac Surg 1998;14:274-8.

11. Sherawat RC, Dixit S, Yadav RK, et al. The place of closed

Cite this article as: Antunes MJ. Closed mitral commissurotomy-a cheap, reproducible and successful way to treat mitral stenosis. J Thorac Dis 2020;12(3):146-149. doi: $10.21037 /$ jtd.2019.12.118 mitral valvotomy in resource-limited countries in the era of catheter-based interventions: 20-year single center experience. J Cardiothorac Surg 2015:31:273-9.

12. Ravikrishnan J, Arun N, Varkey AM. A prospective comparative study between closed mitral valvotomy and balloon valvoplasty as treatment for rheumatic non calcific mitral stenosis. J Evol Med Dent Sci 2015;4:11298-307.

13. Antunes MJ. Challenges in rheumatic valvular disease: surgical strategies for mitral valve preservation. Glob Cardiol Sci Pract 2015;2015:9.

14. Ussiri EV, Nyawawa ETM, Wandwi WBC, et al. Closed mitral valvotomy - a life saving procedure in facilitydeprived countries: Experience at Muhimbili National Hospital, TANZANIA. East and Central Afr J Surg 2011;16:74-9.

15. Radhakrishnan BK, Sreekantan R, Panicker VT, et al. Outcomes of Mitral Valve Replacement after Closed Mitral Valvotomy: A Retrospective Cohort Study. Heart Surg Forum 2019;22:E207-12. 